\title{
EL SALADAR DE BRISTOL: PATRIMONIO VEGETAL, ESTADO DE CONSERVACIÓN Y PROPUESTA DE RESTAURACIÓN (CORRALEJO, FUERTEVENTURA, ISLAS CANARIAS)
}

\author{
Salvador Beato Bergua ${ }^{1}$ \\ Miguel Ángel Poblete Piedrabuena \\ José Luis Marino Alfonso \\ Departamento de Geografía. Universidad de Oviedo. \\ beatosalvador@uniovi.es,mpoblete@uniovi.es, jolumarino@gmail.com
}

\section{RESUMEN}

El Saladar de Bristol tiene valores naturales y paisajísticos de interés científico, educativo, turístico y, por ende, económico. Es de especial relevancia su patrimonio vegetal con una asociación vegetal única en Fuerteventura, Sarcocornietum perennis, y especies catalogadas por su singularidad para Canarias. Sin embargo, sufre una intensa degradación por la presión urbanística (Corralejo) y las amenazas generales que pesan sobre los humedales y zonas litorales turísticas. Por esta razón, se analizan y cartografían sus comunidades vegetales y se proponen medidas para una adecuada conservación y gestión ambiental.

Palabras clave: Patrimonio vegetal, Sarcocornia perennis, Saladar de Bristol, Corralejo, Fuerteventura, Islas Canarias.

\section{ABSTRACT}

Bristol Salt Marsh has natural and landscape values of high scientific, educational, tourist interest and therefore economic. Especially relevant is its plant heritage: a plant association that is unique in Fuerteventura, Sarcocornietum perennis, and species cataloged

Fecha de recepción: marzo 2015.

Fecha de aceptación: diciembre 2015.

1 Investigador del programa "Severo Ochoa" de ayudas predoctorales del Plan de Ciencia, Tecnología e Innovación del Principado de Asturias hasta el 31 de agosto de 2015 y del programa FPU del MECD en la actualidad. 
by its singularity in the Canaries. However, it suffers the typical degradation of intense urban development pressure (Corralejo) and the general threats to wetlands and coastal tourist areas. For this reason its plant communities are analyzed and mapped and measures for a proper conservation and environmental management are proposed.

Keywords: Vegetal Heritage, Sarcocornia perennis, Bristol Salt Marsh, Corralejo, Fuerteventura, Canary Islands.

\section{INTRODUCCIÓN}

La declaración de Fuerteventura como Reserva de la Biosfera en el año 2009 ejemplifica la riqueza del patrimonio natural de la isla y su buen estado de conservación, disponiendo hasta la fecha de un total de 12 espacios protegidos bajo las figuras de Parque Natural (3), Monumento Natural (6), Parque Rural (1) y Paisaje protegido (2); 1 Sitio de Interés Científico (SIC), 9 zonas ZEPA y 12 ZEC.

Las investigaciones sobre dicho patrimonio han sido muy numerosas y de carácter general, en las que se aborda no sólo el análisis de la geomorfología (Romero, 1986; Criado, 1991), el patrimonio volcánico (Dóniz, 2009) y la evolución del relieve (Cubas et al., 1988; Zazo et al., 2008; Criado et al., 2012); sino además aspectos biogeográficos (HernándezCordero et al., 2015), fitosociológicos (Rodríguez et al., 2000) y botánicos (Kunkel, 1977; Santana y Naranjo, 2002), así como la evolución histórica del paisaje vegetal (Criado, 1990) y el conjunto del patrimonio natural de la isla (Rodríguez, 2005). También se han llevado a cabo estudios más puntuales de diversos espacios naturales protegidos, en especial, sobre el Parque Natural de las Dunas de Corralejo e Isla de Lobos (Fernández-Pello et al, 1985; Criado et al., 2004; Criado et al., 2007; Fernández et al., 2012).

Sin embargo, el Saladar de Bristol debido a sus pequeñas dimensiones y a que se halla en la franja periurbana de Corralejo ha pasado desapercibido y no ha sido objeto de ninguna investigación específica, aunque sí aparece citado en investigaciones botánicas sobre especies concretas (Fernández y Santos, 1983) y en trabajos generales sobre la vegetación de la isla y el archipiélago canario (Del Arco et al, 2006), así como en catálogos medioambientales. Pese a su singularidad no se encuentra amparado bajo ninguna figura de protección, que sí se otorgó, en cambio, al Saladar de Jandía (Playa del Matorral), también en Fuerteventura, declarado SIC y ZEC por sus destacados valores naturales.

Teniendo en cuenta que estos saladares costeros son un bien excepcional en las islas Canarias, los principales objetivos de esta investigación se centran en el análisis del patrimonio vegetal del Saladar de Bristol y su entorno, la determinación de su estado de conservación y finalmente la elaboración de medidas de restauración que sirvan de base para una adecuada gestión ambiental y uso racional.

\section{II. ÁREA DE ESTUDIO}

La isla canaria de Fuerteventura es la segunda más grande del archipiélago con una superficie de $1.659 \mathrm{~km}^{2}$ y una de las más orientales, junto con Lanzarote, razón por la cual 
se halla muy cerca del continente africano, en concreto, a menos de $100 \mathrm{~km}$ de distancia, entre $28^{\circ} 45^{\prime} 25.64^{\prime \prime}$ y $28^{\circ} 02^{\prime} 38^{\prime \prime}$ ' de latitud norte y $14^{\circ} 30^{\prime} 35.84^{\prime \prime}$ y $13^{\circ} 49^{\prime} 31.00^{\prime \prime}$ de longitud oeste. En líneas generales, se caracteriza por una orografía relativamente llana especialmente en la zona septentrional y central, sólo accidentada por viejos macizos volcánicos como los de Betancuria, Tetir y Jandía, donde se localiza el Pico de la Zarza que con sus 807 msnm constituye la cumbre de la isla. Desde el punto de vista climático y al igual que el resto del archipiélago, disfruta de un clima determinado por tres factores básicos: la proximidad del continente africano, el predominio de los vientos alisios y la corriente oceánica fría que recorre sus costas (Marzol, 1993). Como resultado son muy frecuentes las inversiones térmicas de tendencia subsidente que originan una marcada estabilidad atmosférica, siendo el máximo responsable de esta situación el anticiclón subtropical de las Azores (Dorta, 1996). Así pues, el rasgo climático más definitorio de Fuerteventura es, sin duda, su extremada sequedad. En concreto, los datos aportados por la AEMET en el Aeropuerto de El Matorral, para la serie 1981-2010, son de una media anual de $97 \mathrm{~mm}$ repartidos entre 15,7 días, lo que implica que apenas llueve un 4,3\% de los días del año. Por otro lado, el reparto de dichas precipitaciones es muy irregular, toda vez que más de la mitad de las lluvias se concentran en invierno $(57,7 \%)$, seguidas del otoño $(23,7 \%)$ y la primavera $(18,6 \%)$; en tanto que en verano no se producen precipitaciones. Si a esta distribución irregular añadimos que las lluvias tienen con frecuencia un marcado carácter torrencial, se explica que constituyan un claro factor restrictivo para el desarrollo de la vegetación y de las formaciones edáficas, puesto que desencadenan escorrentías muy erosivas.

Por otro lado, las temperaturas son muy suaves con una media anual del orden de $21,1^{\circ} \mathrm{C}$, siendo enero el mes más frío con $17,6^{\circ} \mathrm{C}$ y agosto el más caluroso con $24,5^{\circ} \mathrm{C}$. Así pues, la amplitud térmica es muy pequeña de apenas $6,9^{\circ} \mathrm{C}$ y la humedad relativa media es del $70 \%$ merced a la influencia oceánica, a lo que hay que sumar una elevada insolación media con 2.836 horas de sol anuales. Por último, los fuertes vientos que azotan la isla todo el año son otro importante elemento a tener en cuenta en la configuración de la vegetación y como agente erosivo, siendo predominantes los de componente Norte (Criado, 1991) con velocidades medias comprendidas entre 7 y 10 m/s (Ministerio de Medio Ambiente, 2006).

El Saladar o Charco de Bristol, situado al N de la isla de Fuerteventura junto a la localidad de Corralejo, es una pequeña depresión litoral en el malpaís originado por las emisiones lávicas del volcán Bayuyo. Por el NE, una entrada de agua marina de escasos metros atraviesa los basaltos pleistocenos e inunda parcialmente la zona durante las pleamares, aportando continuamente sedimentos marinos y sales minerales que condicionan a las formaciones vegetales y modelan activamente el lugar (Fig. 1). A estos aportes de agua salina hay que añadir los producidos por infiltración, salpicaduras de las olas y el spray marino, que contrastan de manera notable con los de agua dulce extremadamente escasos por el régimen de precipitaciones isleño y la inexistencia de cauces fluviales; si bien durante los episodios torrenciales puede evacuarse un volumen importante de la escorrentía procedente de las cercanías.

Pese a que apenas tiene una extensión de $0,2 \mathrm{~km}^{2}$, no obstante, alberga una gran riqueza natural, integrada por diversos biotopos formados en el contacto entre el mar y la superficie terrestre, sobre un sustrato rocoso configurado tanto por materiales volcánicos como por arcillas, sedimentos marinos y eólicos; sometidos a unas condiciones climáticas áridas y, sobre todo, a una intensa presión antrópica debido a la expansión urbanística de Corralejo. 

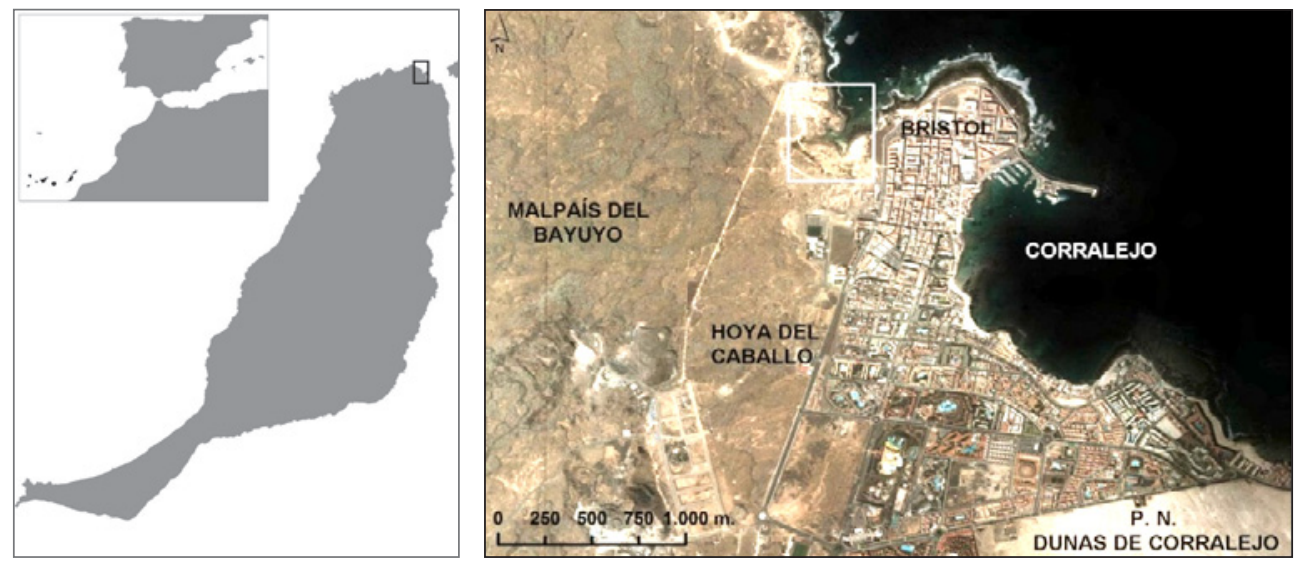

\section{METODOLOGÍA}

La metodología ha consistido básicamente en el trabajo de campo y, en menor medida, en la fotointerpretación de imágenes áreas (años 1981, 1984 y 1989) y del ortofotomapa del PNOA; asimismo en la consulta de la información digitalizada de la Infraestructura de Datos Espaciales de Canarias y del Centro Nacional de Información Geográfica. Tales imágenes, a pesar de su funcionalidad para realizar la cartografía geomorfológica y para distinguir diferentes unidades de vegetación (Hernández-Cordero et al, 2015), han resultado de menor utilidad en el reconocimiento e identificación de algunas comunidades vegetales del saladar, dadas sus pequeñas dimensiones $y$, sobre todo, la escasa impronta que muestran sus tapices vegetales de escaso porte y baja densidad. Por esta razón, el trabajo de campo ha sido muy exhaustivo, llevándose a cabo mediante múltiples itinerarios realizados durante un año, en concreto, entre octubre de 2013 y octubre de 2014, analizando todos los biotopos del área de estudio.

Primero, se realizó un croquis sobre el ortofotomapa del PNOA (correspondiente al vuelo fotogramétrico de 2012) con la identificación, a priori, de las superficies ocupadas por las principales formaciones vegetales en función de la textura, el color y la disposición espacial. La comprobación de los límites de las unidades de vegetación y el estudio fitosociológico en profundidad se acometió mediante dos métodos. Por un lado, se diseñaron diferentes rutas lineales para hacer un muestreo aleatorio estratificado a partir de transectos de un metro de ancho y de varias longitudes. Por otro, se designaron varias parcelas de 2 × 2 metros en las unidades geomorfológicas más representativas (frente litoral, arenales, roquedos, áreas de inundación diaria y ocasional, áreas degradadas por actividades humanas) para efectuar una herborización más minuciosa. Durante los muestreos se procedió al estudio florístico inventariando las plantas vasculares por estratos, delimitando unidades de vegetación a partir de criterios de abundancia/dominancia (escala de Braun-Blanquet) y analizando los factores ecológicos más relevantes con el objetivo de caracterizar, interpretar y cartografiar las distintas comunidades vegetales (Beltrán et al. 1999; Arozena, 2000; Hernández-Cordero et al, 2015). 
Con posterioridad, se efectuó una evaluación del estado de conservación y una tipificación de los peligros que amenazan a la vegetación, estudiando la evolución de los usos e identificando los impactos recientes, en concreto, del tránsito de personas y vehículos, así como de los vertidos efectuados. Finalmente se practicaron entrevistas a visitantes del saladar, a empresarios de la construcción del municipio de la Oliva y a funcionarios del ayuntamiento y del Cabildo de Fuerteventura.

Con toda la información obtenida se procedió a la elaboración de una base de datos incluida en un SIG a partir del software ArcMap, mediante el cual se digitalizaron los polígonos correspondientes a la distribución de las distintas comunidades vegetales y se obtuvieron los cálculos de su superficie, así como la cartografía definitiva detallada; sentando las bases para un futuro seguimiento de la evolución de las comunidades del Saladar de Bristol similares a los realizados en los campos de dunas de Maspalomas y de la isla de La Graciosa (Hernández, A.I. et al., 2014; García, L. et al., 2014).

\section{CARACTERÍSTICAS GEOMORFOLÓGICAS}

La isla de Fuerteventura, al igual que el resto del archipiélago, es de origen volcánico y se ha formado a partir de numerosas erupciones, las más antiguas de las cuales tienen una edad superior a $20 \mathrm{Ma}$. Sin embargo, buena parte de la superficie insular es fruto de un volcanismo cuaternario que se clasifica desde el punto de vista geológico dentro de las Series Volcánicas III y IV del denominado Post-Complejo Basal (Fuster et al., 1968; Ibarrola et al, 1989; Coello et al, 1992; Ancochea et al., 1993). Se trata de un volcanismo de composición basáltica que morfológicamente destaca por la presencia de grandes conos piroclásticos, algunos de los cuales son los de mayores dimensiones de la isla (Serie III); y por la configuración de una cadena volcánica de conos aislados e imbricados concentrados en los sectores central y septentrional de la isla, de edad würmiense (Serie IV). En concreto, esta actividad tiene lugar entre 51.000 B.P. y 26.000 B.P. (Pomel et al, 1985; Criado, 1991).

Así pues, la característica más relevante del relieve del Norte de Fuerteventura es la presencia de la alineación de Montaña Colorada-Bayuyo, compuesta por nueve conos volcánicos dispuestos a lo largo de $5 \mathrm{~km}$ según la directriz estructural NE-SW (Criado, 1991). Las coladas lávicas basálticas procedentes de estos aparatos volcánicos, especialmente de Bayuyo, conforman un amplio malpaís, que no sólo incrementa la superficie isleña en $110 \mathrm{~km}^{2}$ sino que además produce importantes interferencias en los litorales, fosilizando una paleocosta con depósitos marinos y un antiguo jable (Criado, 1991). Sobre dicho malpaís los procesos marinos holocenos modelan en este sector un acantilado de baja altura. Precisamente, el saladar se localiza sobre una depresión excavada en dicho cantil activo, en concreto en el extremo $\mathrm{N}$ de la Hoya del Caballo, donde las lavas disminuyen progresivamente de espesor hasta su contacto con el mar en Bristol y la bahía de Corralejo. Desde el punto de vista morfológico, presentan un aspecto externo escoriáceo y muy caótico con alternancia de pequeñas elevaciones de rocas desnudas por la erosión y depresiones donde se acumulan materiales finos (Fig. 2).

Cabe destacar que el malpaís se va revistiendo progresivamente, hasta alcanzar el veril de la costa, de arenas bioclásticas de origen marino removilizadas allí donde la topografía y la dirección dominante de los vientos lo permiten. Se trata de arenas pleistocenas y holocenas con arcillas y polvo sahariano que formaban un manto eólico sin solución de continuidad con el 
gran jable de Corralejo (Parque Natural de las Dunas de Corralejo), antes de su fragmentación por la expansión urbana de dicha localidad. Las arenas alcanzan mayor espesor en los espacios más llanos y en las depresiones, cubriendo en muchas ocasiones por completo las lavas basálticas, mientras que en las elevaciones pasan a un segundo plano o incluso desaparecen.



El emplazamiento del saladar, al abrigo de las corrientes y del viento procedente del NO, propicia también la acumulación de arenas y limos en la parte más resguardada, donde las condiciones geoambientales son favorables. Al E del saladar hay además un pequeño sistema dunar fijado por la vegetación y limitado por una cubierta de picón decorativo que enlaza con el espacio urbanizado (Fig. 2). En el frente costero está depositada una banda de cantos rodados y aplanados por la acción del oleaje denominado en las islas callao. Forma un cordón de varios metros de ancho que alcanza alturas por encima de los dos metros en el $\mathrm{N}$ del saladar. Además de los cantos se compone también de materiales de origen orgánico como algas calcáreas (confite) y conchas. Finalmente, debajo de estos callaos se extiende una plataforma de abrasión marina cuyos basaltos pleistocenos aparecen cortados a bisel.

\section{CONDICIONANTES CLIMÁTICOS Y EDÁFICOS}

Las condiciones climáticas constituyen uno de los principales factores que influyen en la distribución espacial de las formaciones vegetales, así como en sus rasgos fisionómicos e incluso florísticos. Dichas características son similares en buena parte de la isla de Fuerteventura por lo que aparecen en la descripción general del área de estudio. Conviene 
destacar la escasez de precipitaciones que se acentúa aún más si cabe en esta franja costera septentrional, donde son inferiores a los $100 \mathrm{~mm}$ (Marzol, 1988) y hay además una tasas de evapotranspiración muy altas que pueden superar los $800 \mathrm{~mm}$ anuales (Mora et al., 2009). A esto contribuyen una elevada insolación y temperaturas suaves, a lo que hay que añadir en las zonas costeras como el Bristol los intensos vientos y una elevada salinidad, esto es, un ambiente muy restrictivo que dificulta incluso el desarrollo de la vegetación halófila y xerófila adaptada a estos medios sometidos a un estrés hídrico severo.

A tenor de los datos existentes, el clima del borde costero septentrional de Fuerteventura puede clasificarse como de tipo $B W h s i$ ', a saber, desértico cálido semiisotermo (López y López, 1979). A estas características climáticas regionales hay que añadir otros condicionantes de ámbito local que también afectan a la distribución de la vegetación. Tal es el caso de la topografía que interfiere básicamente en la fuerza y dirección de los vientos, así como en la humedad ambiental procedente del mar.

El suelo es el otro factor básico que explica la disposición de la vegetación halófila del Saladar de Bristol, distinguiéndose hasta cuatro de los principales tipos presentes en la isla. Todos ellos se caracterizan por un régimen de humedad arídico. En concreto, en el centro del saladar hay suelos de tipo salids que presentan una gran cantidad de sales solubles, que ascienden desde la capa freática por la evaporación del agua en superficie. Tienen una textura limosa y baja pedregosidad aunque pueden presentar cantos y bloques transportados en superficie. Por otro lado, el espacio dunar oriental dispone de entisoles de tipo psamments, esto es, suelos de arenas en este caso de origen orgánico marino, sin horizontes diferenciados. Asimismo tienen cierto grado de salinidad por la influencia de la maresía y se hallan nitrificados por la contaminación urbana y la presencia de restos de plantas marinas en descomposición. El resto del área lo ocupan lavas basálticas sin desarrollo de suelo y orthents, a saber, suelos pedregosos de escaso o nulo espesor y con contenido salino, a veces carbonatados, asociados a otros un poco más evolucionados (calcids). Según la clasificación de suelos de la FAO/UNESCO se catalogarían de forma general dentro de los grupos de suelos salinos o solonchaks, muy arenosos o arenosoles y afloramientos rocosos o leptosoles respectivamente; además de los antrosoles en las zonas empleadas para pequeñas construcciones o como escombreras en las últimas décadas del siglo XX.

\section{PATRIMONIO VEGETAL}

El Saladar de Bristol, perteneciente al piso bioclimático inframediterráneo inferior desértico árido inferior, está formado por comunidades de plantas higrófilas, halófilas, xerófilas y psamófilas que biogeográficamente se localizan en el Sector Majorero de la Subprovincia Canaria Oriental (Rivas-Martínez et al., 2002). Su patrimonio vegetal más significativo se integra en el ecosistema denominado "Matorral halófilo termoatlántico" poco representado en la región macaronésica europea por la escasez de franjas litorales llanas. Se trata de un hábitat caracterizado por la asociación vegetal Salicornietea fruticosae Br.-B1. \& Tüxen 1943, donde predominan los matorrales de quenopodiáceas constituidos por formaciones leñosas perennes de suelos salinos (Rivas-Martínez et al., 2002; Del Arco et al, 2006; Del Arco et al, 2010). Si bien el área potencial para el conjunto de los saladares canarios se calcula en una superficie de 362 ha, sin embargo, sólo se conservan 304 ha (Del Arco et al, 2010), al emplazarse en zonas costeras 
sometidas a una fuerte presión antrópica, tal y como sucede en Bristol. No obstante, son formaciones vegetales de gran valor e interés al representar ecosistemas de gran singularidad (Fig. 3).

La riqueza y diversidad vegetal del Charco de Bristol y su entorno, con presencia de numerosos biotopos, están determinados por varios factores entre los cuales cabe señalar la morfología del relieve, las características del sustrato, la distancia a la costa y los procesos de deflación y sedimentación eólica (Hernández et al., 2015). Así, a poniente, en la parte superior de los callaos de toda la orla litoral y en su borde posterior se desarrolla el denominado matorral halófilo costero de roca (Frankenio ericifoliae - Zygophylletum fontanesii), asociación vegetal que se conserva en buena medida en el cinturón rocoso de las costas áridas e hiperáridas de las islas orientales y de Tenerife (Del Arco et al, 2006; Del Arco et al, 2010); alcanzando, en concreto, en la isla de Fuerteventura una extensión de unas 404 ha (Del Arco et al, 2010). Detrás aparecen sobre el recubrimiento arenoso-arcilloso las comunidades propias de saladar: las asociaciones Zygophyllo fontanesii - Arthrocnemetum macrostachyi (saladar genuino) y Frankenio capitatae - Suadetum verae (saladar de mato moro).

Figura 3

ESQUEMA CARTOGRÁFICO DE LAS COMUNIDADES VEGETALES DEL SALADAR DE BRISTOL

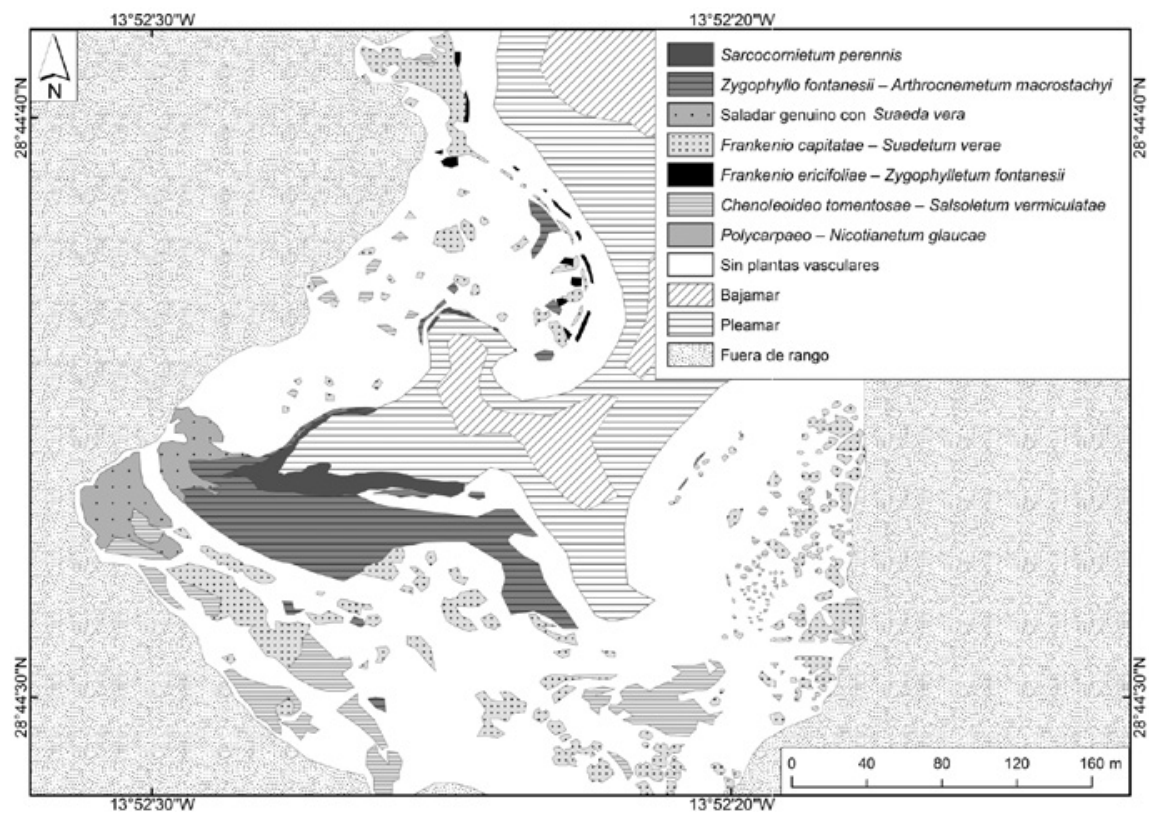

Una acumulación lávica de unos tres metros de altura protege la depresión que alberga el saladar y pese a estar prácticamente desprovista de vegetación por la falta de suelo y humedad edáfica, se halla recubierta de líquenes, algunos ejemplares de Suaeda vera y especies propias del matorral nitrófilo árido de sustitución. Tales basaltos están atravesados por un canal natural de más de 100 m de largo, por el que el mar rompe la plataforma de abrasión labrada sobre ellos e inunda la pequeña depresión del Bristol. Esta entrada de agua marina 
se abre hacia poniente, donde la menor influencia del oleaje y de los vientos facilita la deposición de lodos en el espacio intramareal y el desarrollo de Sarcocornia perennis. La asociación característica de esta especie, a saber, la Sarcocornietum perennis junto a las anteriormente mencionadas están definidas en la Directiva de Hábitats de la Unión Europea como de interés comunitario (Espinar, 2009).

Tras la primera orla de vegetación del saladar propiamente dicho, aparecen hacia el S y el O las manchas más importantes de vegetación. Se corresponden de nuevo con Zygophyllo fontanesii-Arthrocnemetum macrostachyi y Frankenio capitatae - Suadetum verae que se desarrollan sobre esta área deprimida del malpaís entre 0 y $1 \mathrm{~m}$ de altitud, cubierta por arcillas y arenas y gran contenido salino (Fig. 4). Por otro lado, la mayor energía de las aguas, en la terminación meridional del canal, atraviesa los callaos que lo bordean, generando una superficie tendida de arena que conecta con el espacio dunar situado al Este. La alteración antrópica es muy intensa en esta zona lo que explica que la fijación de las pequeñas dunas se produzca por matorrales de sustitución (Chenoleoideo tomentosae - Suaedetum mollis), que conviven con algunas plantas halófilas y otras especies ruderales fruticosas. La inclusión del saladar en el área urbana de Corralejo se plasma además en la deposición de un manto de picón con fines decorativos, en el que están presentes las comunidades mencionadas y especies de las asociaciones Salsolo kali - Cakiletum maritimae y Polycarpo - Nicotianetum glaucae. Finalmente, los diferentes matorrales de sustitución, nitrófilo árido y nitrófilo de mimos, se explayan de forma creciente según nos alejamos del núcleo del saladar hacia el perímetro urbano.

Figura 4

CATENAS DE VEGETACIÓN DEL SALADAR DE BRISTOL

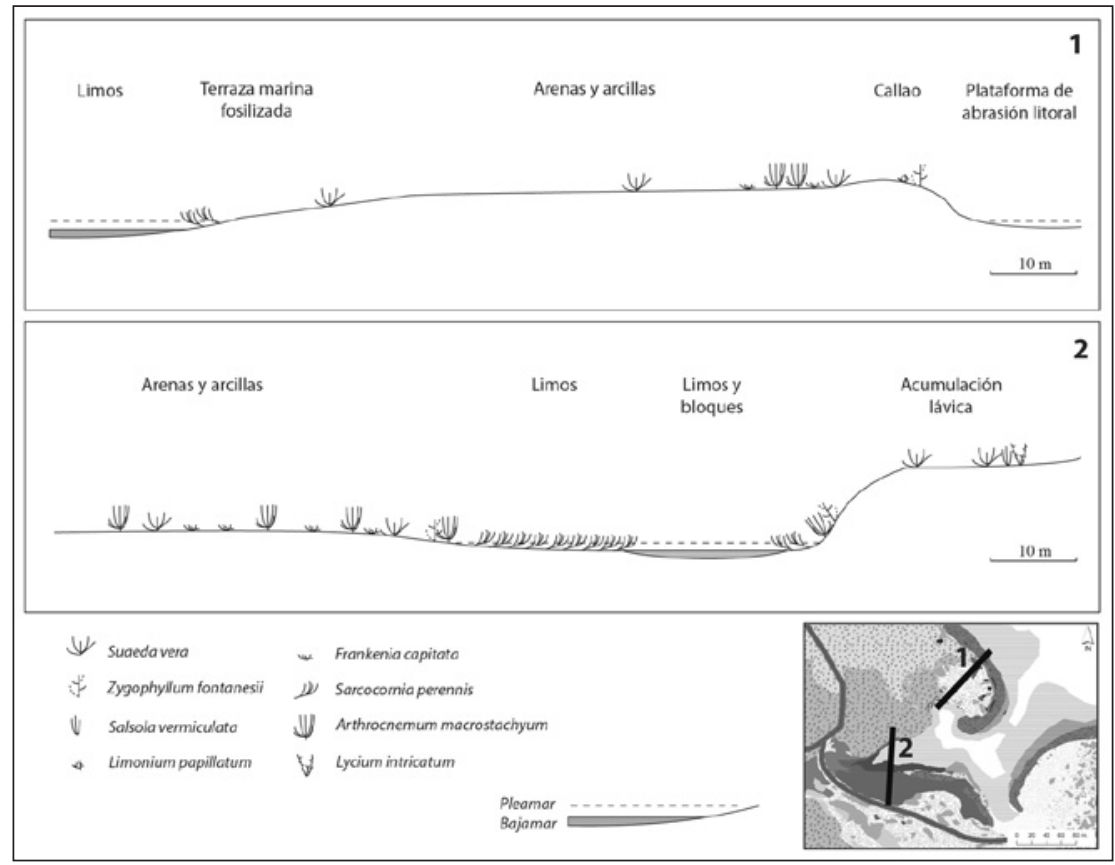


En definitiva, la vegetación del saladar presenta la zonificación típica de estos humedales en relación directa con el nivel de tolerancia de las plantas a la inundación (Fig. 4). Así, el orden desde el centro al exterior es el siguiente: saladar cespitoso encharcado, saladar genuino, saladar genuino con mato moro y saladar de matomoro.

A su vez, se puede establecer otra estructura de distribución en función de la influencia de la maresía y la tolerancia de las plantas a las sales. De este modo, situaríamos en primer lugar el matorral halófilo costero de roca y por detrás, en una segunda orla de vegetación, manchas prácticamente monoespecíficas de Suaeda vera, además de matorral nitrófilo de arenas o árido en función del sustrato y el nivel de antropización.

\section{VI.1. Saladar cespitoso encharcado o de marisma}

Se corresponde con la asociación Sarcocornietum perennis (Fernández y Santos, 1983) situada en la transición del infraestero al supraestero del saladar de Bristol, es decir, en el nivel inferior, resistiendo la inundación parcial por las pleamares dos veces al día. Prospera, por tanto, sobre materiales muy limosos depositados por el mar y se caracteriza por configurar una alfombra o césped continuo, al tratarse de una planta muy ramificada con tallos articulados carnosos en la parte superior, donde se acumulan las sales, y leñosos en la base. Esta comunidad de Sarcocornia perennis (Fig. 5) es única en toda la isla de Fuerteventura y se halla presente también en otros tres enclaves de las islas Canarias orientales (Del Arco et $a l, 2006)$, por lo que está incluida en el Catálogo de Especies Amenazadas de Canarias como especie de alto interés. B Y C) ASOCIACIÓN SARCOCORNIETUM PERENNIS ATRAVESADA POR SENDAS

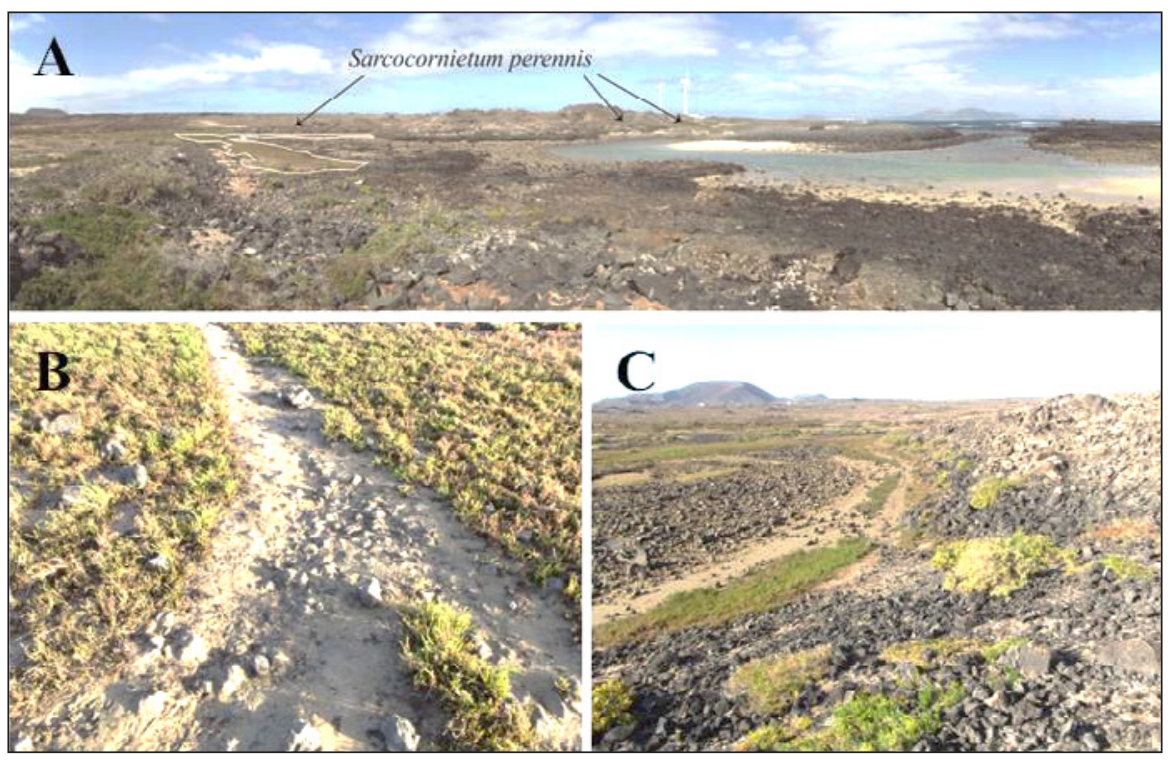


Se estima que Sarcocornia perennis se distribuye en cuatro cuadrículas UTM de $500 \mathrm{~m}$ de lado, esto es, diseminada por una superficie de $1,75 \mathrm{~km}^{2}$ en Fuerteventura y en Lobos (Morales, 2009). Por otro lado, en una investigación de seguimiento llevada a cabo por Santana y Naranjo (2002) señalaban que tenía una extensión de $4.000 \mathrm{~m}^{2}$ en la isla, es decir, en el Saladar de Bristol, pues es el único enclave de Fuerteventura; cifra que parece excesiva en función del área propicia para su desarrollo. En realidad, los datos que hemos obtenido durante las campañas de campo y los cálculos realizados mediante SIG arrojan una cifra de apenas $1.247 \mathrm{~m}^{2}$.

A tenor de lo expuesto se explica la fragilidad de esta especie y de su hábitat sumamente vulnerable, a lo que hay que sumar la elevada presión antrópica que se manifiesta en los desechos urbanos que devuelve el mar a la costa, los residuos de hidrocarburos, el trazado de sendas y el intenso pisoteo al tratarse de una zona de tránsito de personas y mascotas.

\section{VI.2. Saladar genuino}

La comunidad Zygophyllo fontanesii-Arthrocnemetum macrostachyi as. nova. (Fernández y Santos, 1983) constituye la segunda orla del saladar ocupando el supraestero, no obstante, aparecen individuos de Arthrocnemum macrostachyum y Tetraena fontanesii en el límite superior del infraestero. De este modo Arthrocnemum macrostachyum, también conocida como sapillo, acompaña en algunos puntos a Sarcocornia perennis resistiendo, por tanto, parciales inundaciones. Presenta también tallos leñosos por la base pero articulados y carnosos por encima, sin embargo, se extiende en forma de matas dispersas de hasta 1,50 $\mathrm{m}$ de altura, siendo un arbusto generalmente erguido aunque aparezca en ocasiones de forma postrada. Hacia el interior tiene que resistir largos períodos de sequía y la intromisión de Suaeda vera ya en zonas arenosas y arcillo-arenosas (siempre salinas) alejadas de las mareas diarias (Fig. 4). El papel de Arthrocnemum macrostachyum en las interacciones biológicas es muy interesante en cuanto a que modifica aspectos físico-químicos del suelo (Sadek y Eldarier, 1995; Pugnaire et al. 2004; Espinar, 2009), facilitando la colonización de otras especies. Junto con Suaeda vera abarca una gran extensión en el Oeste de Bristol, formando una cobertura densa y continua interrumpida por un camino de tierra para vehículos. En esta asociación no hay un claro dominio de una especie sobre otra, por lo que se ha decidido cartografiarla como un polígono diferente de Zygophyllo fontanesii - Arthrocnemetum macrostachyi (saladar genuino con Suaeda vera).

Arthrocnemum macrostachyum también es una especie incluida dentro del Catálogo Canario de Especies Protegidas del año 2010, que figura como de interés especial para los ecosistemas canarios. En la evaluación de 2009 encargada por el gobierno canario, pese a que parecía presentar cierta estabilidad, se consideró que tenía una tendencia regresiva en virtud de los datos de décadas anteriores y de su localización en áreas de interés urbanístico (Rodríguez y Valdivia, 2009). En el Saladar de Bristol se halla amenazada por las mismas alteraciones de su hábitat que sufre Sarcocornia perennis, además de por el tránsito de vehículos a motor y el vertido de escombros (Fig. 6).

Arthrocnemum macrostachyum se acompaña de Tetraena fontanesii (popularmente conocida como "uva de mar") en la asociación del saladar genuino. Este arbusto suculento de hasta medio metro de altura está repartido por todo el litoral de Fuerteventura. Se trata igualmente de una especie halófila: se desarrolla tanto sobre sustrato arenoso y arcilloso (prefiriendo el área de influencia de las salpicaduras y el spray marino) como rocoso, apareciendo 
sobre los callaos dentro de la asociación de matorral halófilo costero de roca (Fig. 7). Se despliega por todo el Charco de Bristol de forma muy dispersa pero constante y con escaso porte a medida que se aleja de la influencia marina. Algunos individuos aislados se sitúan a más de 50 metros de la línea de costa junto a vegetación psamófila, merced a su resistencia a la sequía y a la insolación. Su amplia distribución en prácticamente todas las islas Canarias justifica su exclusión de los catálogos de protección.

Figura 6

IMAGEN AÉREA Y FOTOGRAFÍA DE LA COMUNIDAD DE SALADAR GENUINO ATRAVESADA POR UNA PISTA PARA VEHÍCULOS Y SENDAS
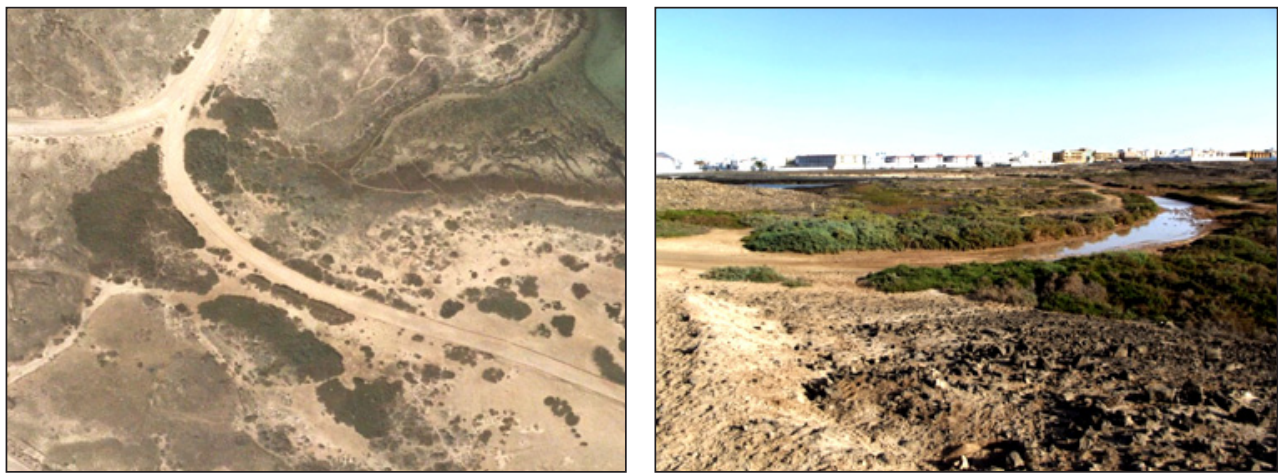

Figura 7

MAPA DE LOCALIZACIÓN DE LAS ESPECIES VEGETALES INVENTARIADAS

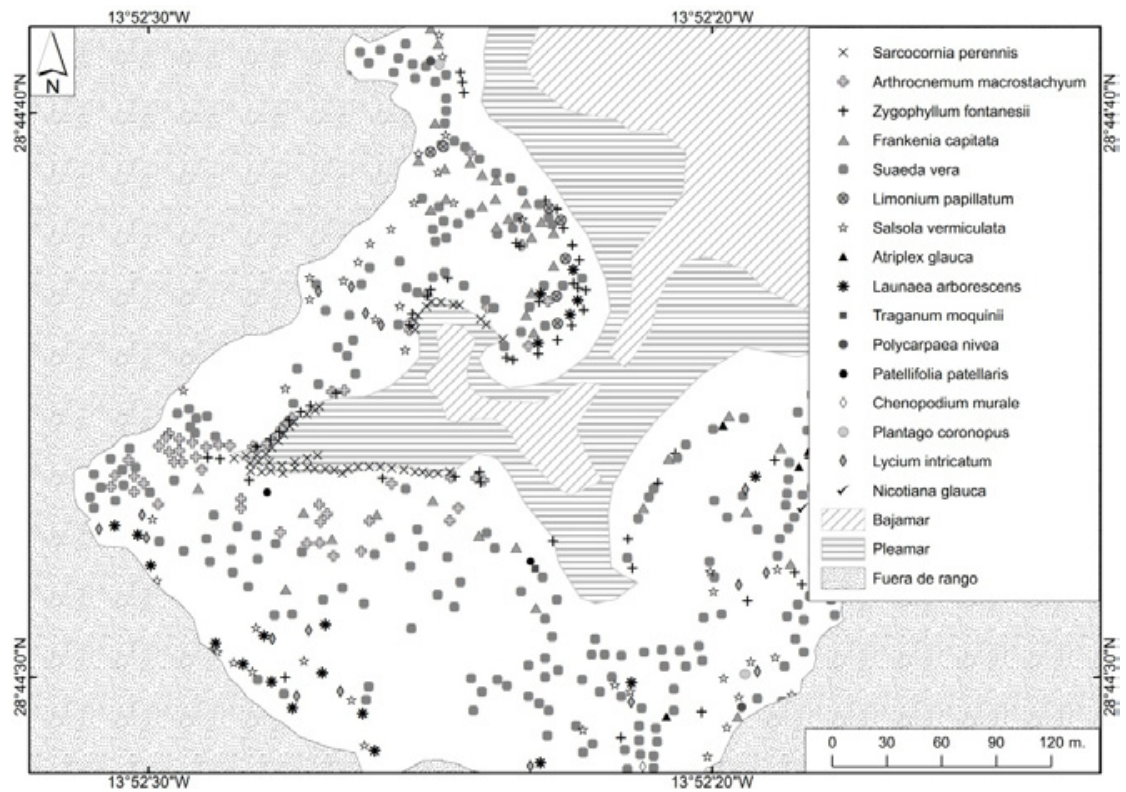


La tercera especie reconocida dentro de esta asociación es Frankenia laevis var. capitata o matilla parda muy extendida en Bristol y sus alrededores. Esta planta de pequeño porte (no más de $30 \mathrm{~cm}$ ) se difunde sobre una gran superficie aunque de forma muy aclarada (áreas que en fotointerpretación parecen carentes de vegetación se descubren totalmente colonizadas por esta especie en el trabajo de campo). También encontramos la ya mencionada Suaeda vera con matas que cubren hasta $2 \mathrm{~m}^{2}$ de superficie y algunos individuos de Mesembryanthemum nodiflorum.

\section{Vl.3. Saladar de mato moro}

El mato moro (Suaeda vera) es un arbusto que presenta tallos leñosos no articulados y glabros, tanto postrados como erectos, entre el decímetro y el metro y medio de altura. Se localiza en suelos salinos tanto arenosos como arcillosos o pedregosos, con humedad aportada por capilaridad o por la maresía y un cierto grado de nitrificación (Fernández y Santos, 1983). Bien distribuido en todas las depresiones costeras de Fuerteventura y los barrancos donde transcurre agua salobre, llega a alcanzar importantes coberturas motivo por el que no aparece incluido en ningún catálogo para su protección.

Se encuentra muy bien representado en todo el saladar del Bristol formando comunidades prácticamente monoespecíficas. Además de participar en asociaciones como la que nos ocupa (Frankenio capitatae - Suaedetum verae) y la del ya comentado saladar genuino donde domina Arthrocnemum macrostachyum, podemos hallar este taxón en la asociación del cinturón halófilo costero Frankenio ericifoliae - Zygophyllum fontanesii y en las de matorral de sustitución Chenoleoideo tomentosae - Salsoletum vermiculatae y Chenoleoideo tomentosae - Suadetum mollis; siempre que se den las condiciones geoecológicas de salinidad, humedad y nitrificación que requiere. Puede soportar inundaciones esporádicas pero en la depresión del Bristol se mantiene en la orla de vegetación posterior a las comunidades de saladar de marisma y de saladar genuino fuera del infraestero. Lo mismo ocurre respecto al matorral halófilo costero de roca, situándose normalmente tras los callaos en un segundo plano y en zonas de arenas y arcillas compactadas (Padrón, 2012).

Aunque pueden aparecer algunos ejemplares con pequeño porte y de forma aislada, se presenta en mayor medida en forma de matas densas que llegan a alcanzar un recubrimiento importante y que apenas dejan espacio para otras especies (Frankenia laevis var. capitata), salvo cuando figura junto a Arthrocnemum macrostachyum en el saladar o junto a Launaea arborescens y Salsola vermiculata en sus márgenes.

\section{VI.4. Matorral halófilo costero de roca}

Esta asociación haloanemógena rupestre litoral, ampliamente expandida sobre los acantilados y depósitos de cantos rodados de toda la costa majorera, tiene también gran presencia en Bristol. Se desarrolla en lugares donde puede recibir los aportes de salinidad que necesita directamente del mar pero sin ser inundada, en suelos de tipo leptosol lítico también severamente cargados de sales (Mora et al., 2009). Por lo tanto, los callaos depositados justo en el frente costero son su residencia preferida, al hallarse elevados por encima del nivel de las pleamares y sobre sustrato rocoso que drena fácilmente los aportes 
hídricos. La comunidad Frankenio capitatae - Zygophyllum fontanesii no forma manchas densas de vegetación más bien todo lo contrario, tratándose básicamente de individuos más o menos aislados y desperdigados.

En la zona oriental del Saladar del Bristol las especies características de esta asociación (Zygophyllum fontanesii y Frankenia laevis var. capitata) se emplazan sobre los cantos redondeados del callao que se interpone entre el mar y el espacio dunar. Aparecen de forma escasa y dispersa con la intromisión de algunas matas de Suaeda vera que alcanzan mayor superficie. En este sentido, Rodríguez et al. (2000) señalan la constitución de una nueva subasociación endémica de la isla de Fuerteventura, Frankenio capitatae - Zygophylletum fontanesii suaedetosum verae, coincidiendo esta dominancia del mato moro con la que se produce en la zona norte del área de estudio y en general en buena parte del litoral septentrional majorero.

Por otro lado, Limonium papillatum enriquece esta comunidad creciendo en la zona occidental bajo la influencia de los vientos dominantes y el spray marino, tanto sobre el callao como en sustrato arenoso y rocoso. La denominada "siempreviva zigzag" es un endemismo canario incluido en el Catálogo Canario de Especies Protegidas por su fragilidad ante la alteración de su hábitat. Es una planta muy característica, de pequeño porte (entre los 10 y 15 $\mathrm{cm}$ de altura), de ramas postradas e inflorescencias zigzagueantes y papilosas con florecillas rosadas y blanquecinas. Se presenta de forma dispersa observándose algunos individuos muy aislados sobre el callao y en menor medida tras éste, participando en otras asociaciones como las de los matorrales de sustitución (Fig. 7).

\section{VI.5. Matorrales de sustitución}

La profunda transformación del paisaje vegetal que ha sufrido la isla de Fuerteventura (Criado, 1991) explica la gran expansión que tienen actualmente las asociaciones de vegetación ruderal fruticosa. En el saladar de Bristol y su entorno se distinguen diferentes formas de matorral de sustitución. En concreto, sobre suelos arenosos más o menos compactados y con constante influencia aerohalina se desarrolla Chenoleoideo tomentosae - Salsoletum vermiculatae. Es el caso por ejemplo de las pequeñas dunas orientales donde Salsola vermiculata, Chenoleoides tormentosa y Lycium intricatum participan en la inmovilización de las mismas. En algunos puntos de las orlas posteriores al saladar aparece Suaeda mollis en lugar de Salsola vermiculata, hablando entonces de la asociación Chenoleo tomentosae - Suaedetum molli; identificada en Bristol en trabajos botánicos especializados (Padrón, 2012). Estas comunidades nitrófilas se propagan prácticamente por toda la isla debido a la degradación antrópica y en el entorno del saladar gana dominancia hacia el interior, con una importante presencia de la aulaga (Launaea arborescens).

Por su parte, la gran amplitud ecológica de Suaeda vera le garantiza también, como ya hemos mencionado, una extensión importante en casi todas las comunidades vegetales presentes en el Saladar del Bristol, incluidas las del matorral nitrófilo árido. También Tetraena fontanesii o Frankenia laevis var. capitata participan o conviven con estas asociaciones vegetales postizas, siempre bajo la influencia aerohalina.

Hacia el oeste, sobre el picón decorativo y en sus cercanías hay especies del matorral nitrófilo de mimos (Nicotiana glauca). 


\section{VI.6. Listado de especies inventariadas}

También hemos identificado otros taxones propios de los matorrales halófilos como Atriplex glauca, algunos del herbazal nitro-halófilo de arenas (Cakile maritima, Salsola kali), del matorral nitro-psamófilo (Polycarpaea nivea) y otros de amplia distribución como Patellifolia patellaris (Tabla 1). En el exterior del saladar hay también plantas propias de ambientes urbanos y suelos nitrificados como Chenopodium murale. En total han sido catalogadas 31 especies pertenecientes a 25 géneros y 12 familias.

Tabla 1

PLANTAS VASCULARES INVENTARIADAS

\begin{tabular}{|l|l|}
\hline Aizoaceae & Chenoleoides tomentosa (Lowe) Botsch. \\
Aizoon canariense & Patellifolia patellaris (Moq.) S.F.L. \& W. \\
Mesembryanthemum crystallinum L. & Salsola kali L. \\
Mesembryanthemum nodiflorum L. & Salsola vermiculata L. \\
Asteraceae & Sarcocornia perennis (Mill.) A.J. Scott subsp. Perennis \\
Filago desertorum & Suaeda mollis \\
Launaea arborescens (Batt.) Murb. & Suaeda vera Forssk. ex J.F. Gmel. \\
Senecio leucanthemifolius & Traganum moquinii \\
Sonchus oleraceus & Fabaceae \\
Brassicaceae & Lotus glinoides \\
Cakile maritima Scop. & Frankeniaceae \\
Caryophyllaceae & Frankenia laevis var. Capitata \\
Polycarpaea nivea (Ait.) Webb. & Plantaginaceae \\
Convolvulaceae & Plantago coronopus L. \\
Cuscuta approximata Bab. & Plumbaginaceae \\
Chenopodiaceae & Limonium papillatum (Webb ex Boiss.) Kuntze \\
Arthrocnemum macrostachyum (Moris) & Solanaceae \\
Atriplex glauca L. var. ifniensis (Caballero) & Lycium intrincatum Boiss. \\
Atriplex lindeyi & Nicotiana glauca Grah. \\
Atriplex semilunaris & Zygophyllaceae \\
Chenopodium murale & Tetraena fontanesii (Webb \& Berthel.) Beier \& Thulin \\
\hline
\end{tabular}

Fuente: elaboración propia.

\section{ESTADO DE CONSERVACIÓN DEL SALADAR DE BRISTOL}

A pesar de la riqueza del patrimonio vegetal del Saladar de Bristol y su relevancia regional, se han realizado actividades poco adecuadas para la conservación de los valores naturales y paisajísticos de este espacio. Debido, en parte, al desconocimiento de su valor e interés natural y por su situación en la "puerta falsa" de una localidad que construía su fachada en el lado opuesto (de cara a la bahía). No obstante, el factor responsable de la degradación, 
tanto de Bristol como de todas las zonas costeras canarias, en general, ha sido el modelo de desarrollo económico basado en el turismo de masas y la consecuente urbanización desorbitada (Fernández-Cabrera et al, 2011), alterando los procesos ecológicos y provocando una pérdida de patrimonio natural y cultural (Pérez-Chacón et al., 2007).

Prácticamente todas las modificaciones territoriales recientes en la isla de Fuerteventura, también en el saladar de forma indirecta, tienen su origen en el auge turístico y sus repercusiones sobre la dinámica demográfica y económica. Según los datos proporcionados por el Instituto Canario de Estadística (ISTAC), el turismo en la isla ha experimentado una enorme progresión en las últimas décadas, recibiendo en 2014 más de dos millones de visitantes; superando así el récord histórico de 2011 con destinos principales en Corralejo y las playas de Sotavento. Esto se ha visto reflejado en los datos de población: el municipio de La Oliva, al que pertenece la localidad de Corralejo, desde 1900 a 1980 osciló entre 2.200 y 3.300 habitantes (ISTAC y el padrón municipal de habitantes) y sin embargo en 1990 sobrepasaba ya los 6.000 habitantes, merced a la llegada de trabajadores para satisfacer la demanda del sector servicios (hostelería y comercio) y la construcción. No obstante, el aumento más espectacular se produce entre los años 2000 y 2014, creciendo de 10.578 habitantes a 24.307. En este periodo, el mayor auge demográfico en La Oliva acontece en Corralejo que pasa de 6.075 a 16.319 habitantes, lo que representa una subida de más del $166 \%$.

Este desarrollo demográfico y turístico y sus implicaciones económicas han tenido importantes repercusiones culturales, territoriales y paisajísticas en la isla (Fernández-Cabrera et al., 2011; Santana et al., 2011). El núcleo urbano de Corralejo se ha expandido con el único impedimento de las fronteras naturales que imponían el mar y los relieves volcánicos. En concreto, se ha pasado de 6,72 ha construidas en 1969 a casi 321 ha ocupadas por edificaciones en 2009 (Fernández-Cabrera et al., 2011), extendiéndose hasta constreñir toda la demarcación del Parque Natural de las Dunas de Corralejo y condicionando así las dinámicas naturales que mantienen este espacio (ASCAN, 1981; Fernández et al, 1982; Dirección General de Costas, 2006; Pérez-Chacón et al., 2007; Fernández-Cabrera et al., 2011).

Por el noroeste, el territorio urbano también ha ido colonizando el espacio hasta adueñarse del Saladar de Bristol. Ya en las fotografías aéreas de 1981 (Instituto de Reforma y Desarrollo Agrario) se observan los primeros bloques de apartamentos en las cercanías (hoy en el tramo final de la Avenida Juan Carlos I). En la misma imagen se aprecia la utilización de toda el área meridional del saladar como escombrera y depósito de materiales, en tanto que en fotogramas posteriores se observa incluso la extracción de arenas en el borde oriental. Tras el cese de estas actividades, los restos fueron extendidos recubriendo los depósitos originales, esto es, las arenas organógenas y arcillas, trastocando definitivamente el tapiz vegetal.

En la década de los noventa se puso en funcionamiento, al noroeste del Charco de Bristol, la planta desalinizadora de agua de Corralejo, mientras que al sur se construye el Instituto de Enseñanza Secundaria y se habilitan zonas de depósito y acopio de materiales para la construcción, así como vertidos de escombros y basura; cercando y englobando definitivamente este espacio al entorno urbano, no obstante, aún conserva su etiqueta de "natural" por la pervivencia de algunos de sus valores paisajísticos y de sus formaciones vegetales originales.

Por otro lado, el extremo norte del saladar también albergó un conjunto de casetas fruto de una actividad pesquera de bajura, tal y como se aprecia en las fotografías aéreas del Vuelo 
Interministerial de 1981 y del Vuelo Nacional de 1984 (Instituto Geográfico Nacional). Tales construcciones ya no se observan en las imágenes del Vuelo de Costas de 1989 (Dirección General de Costas del Ministerio de Medio Ambiente) aunque aún hoy en día se conserva su impronta: restos de cimientos, hitos de hormigón y pistas de acceso.

En cualquier caso, el elemento más perturbador del Saladar de Bristol es la pista que lo atraviesa presente ya en 1945 como camino vecinal en la hoja n ${ }^{\circ} 1092$ del Mapa Topográfico Nacional a E. 1:50.000 del IGN. En la actualidad, se trata de un vial no asfaltado que bordea el norte de la isla de Fuerteventura desde el Faro del Tostón hasta Corralejo. Soporta un tráfico relativamente elevado por lo que el ayuntamiento lleva a cabo constantes labores de mantenimiento con maquinaria pesada. Esta pista atraviesa una de las comunidades vegetales más significativas del Charco de Bristol, esto es, el saladar genuino y permite además el acceso en coche a todos los puntos del saladar a través de las numerosos caminos que se derivan de él o directamente "campo a través", donde la topografía lo permite.

Ante esta situación de deterioro, si bien es cierto que el ayuntamiento de La Oliva ha tomado conciencia en los últimos años de la importancia del Saladar de Bristol, sin embargo, no ha puesto en práctica ninguna medida eficaz destinada a su recuperación. Como ejemplo cabe señalar que hace unos diez años impulsaron la habilitación fuera del saladar de otra carretera para vehículos (pero resultó ilegal al abrirse en propiedad privada), la instalación de un panel informativo (básicamente con el nombre del enclave), un cierre con estacas de madera que nunca se completó; así como la deposición de un manto de picón sobre el arenal oriental que más bien sirvió para la entrada de especies vegetales foráneas. Por otro lado, también han colaborado en labores de limpieza promovidas en ocasiones por los propios movimientos vecinales de Corralejo, lo que es insuficiente a todas luces para su conservación.

Pese a todo, las comunidades vegetales del saladar presentan en los últimos años un estado de conservación relativamente estable tras un largo periodo de fuerte regresión.

\section{PROPUESTA DE RESTAURACIÓN DEL PATRIMONIO VEGETAL DEL SALADAR DE BRISTOL}

El cambio de sistema productivo acaecido en los últimos cuarenta años en Fuerteventura, en el que las actividades tradicionales (agricultura, ganadería y pesca) han sido sustituidas básicamente por un turismo de masas de "sol y playa", ha producido, por un lado, una revalorización económica del ámbito costero y, por otro, ha supuesto una intensa degradación de sus paisajes; como consecuencia de un incremento notable de la población de las villas costeras y sobre todo de una desenfrenada expansión urbano-turística. Así pues, el litoral es el ámbito geográfico de mayor fragilidad dentro del conjunto de la isla de Fuerteventura, que se acentúa aún más si cabe cuando se trata de humedales costeros de pequeñas dimensiones y con comunidades vegetales de pequeño porte, que apenas son apreciadas y además se hallan en el ámbito de crecimiento urbanístico de las ciudades turísticas. Tal es el caso del Saladar de Bristol sometido, como ya hemos visto, a un sinfín de amenazas que cuestionan su presente y vaticinan un futuro poco alentador, si las autoridades competentes no se apremian a adoptar medidas encaminadas a su recuperación y conservación. Dichas medidas han de tener como objetivo final la declaración del Charco de Bristol como Sitio de Interés Científico, jugando un papel activo en el conjunto de los recursos naturales para impulsar el 
desarrollo de sectores emergentes como el turismo de calidad, basado en la sostenibilidad y muy interesado por el conocimiento de la naturaleza y la dinámica del paisaje. Esta categoría de espacio natural protegido está destinada a "lugares naturales, generalmente aislados y de reducida dimensión, donde existen elementos naturales de interés científico, especímenes o poblaciones animales o vegetales amenazadas de extinción o merecedoras de medidas específicas de conservación temporal" (Texto Refundido de las Leyes de Ordenación del Territorio de Canarias y de Espacios Naturales de Canarias, Decreto Legislativo 1/2000, de 8 de mayo), por lo que se presenta como la más adecuada en primera instancia. No obstante, su valor natural no se reduce a un único elemento sino que dentro de su patrimonio hay hábitats de interés comunitario y alta diversidad vegetal; así como diversos biotopos, geoformas, zonas de alimentación de aves y hábitats marinos supralitorales sedimentarios singulares en Fuerteventura. Además, el Saladar de Bristol y su entorno forman parte del patrimonio cultural majorero por sus restos arqueológicos y tradicionales y por su riqueza paisajística, por lo que cabría ampararlo bajo otras figuras de protección.

Para tal fin elaboramos una propuesta de restauración distinguiendo 5 unidades: zona de exclusión, zonas de uso restringido (rehabilitación 1, rehabilitación 2 y rehabilitación 3) y zona de uso moderado (Fig. 8). Terminado el proceso, la zonificación quedaría compuesta por una zona de exclusión y una zona de uso moderado. No obstante, se podría incluir toda el área cubierta por picón, al Este del Charco, como zona de uso general para albergar instalaciones, actividades y servicios.

\section{Zona de exclusión}

Se circunscribe a la parte central del Saladar de Bristol con la finalidad de suprimir el tránsito de personas y animales domésticos por las sendas que atraviesan la comunidad formada por la asociación Sarcocornietum perennis. La disminución del pisoteo y la menor compactación del suelo favorecerán, sin duda alguna, su progresiva recuperación y conexión con las diferentes agrupaciones de salado de marisma. Este sector también engloba la principal mancha de vegetación de saladar genuino. Sólo se permitirá el acceso, previa autorización de las instituciones pertinentes, a personal investigador y de conservación. La mejor forma de recuperar las comunidades vegetales es promoviendo la investigación y la divulgación científica mediante programas institucionales de evaluación y seguimiento, así como la creación de un equipo de mantenimiento que controle la deposición de desechos procedentes del mar.

\section{Zona de uso restringido (Restauración 1)}

En esta pequeña área aparece la asociación Zygophyllo fontanesii - Arthrocnemetum macrostachyi en convivencia con Suaeda vera (saladar genuino con "matomoro"). Está desconectada del núcleo del saladar por una pista que lo atraviesa y se halla además afectada por una escombrera que yace en su interior. Se propone, en primer lugar, la eliminación de la escombrera y la recuperación de la pista mediante la regeneración de un suelo apropiado para el crecimiento de dicha comunidad vegetal. Una vez rehabilitada se integraría a la zona de exclusión configurando el área de mayor interés científico. 


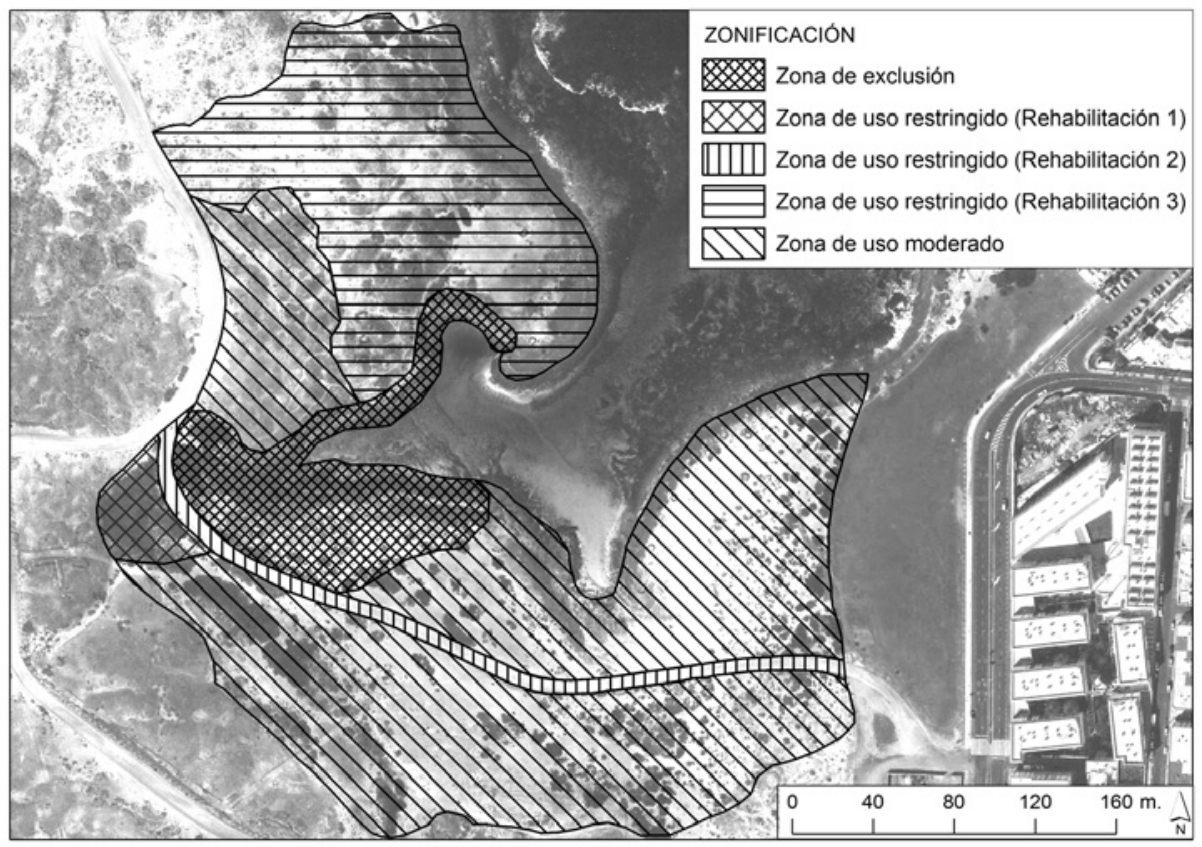

\section{Zona de uso restringido (Restauración 2)}

Se corresponde con la pista que atraviesa el saladar. La medida prioritaria es la supresión del tráfico prohibiendo para ello el acceso a toda clase de vehículos. El trazado de este viario servirá para la creación de una pasarela de madera elevada con pequeños miradores y paneles explicativos, por debajo de la cual habría que regenerar una cubierta edáfica adecuada para ser colonizada por las principales especies potenciales tales como el sapillo, la matilla parda y el mato moro. Concluida la rehabilitación formaría parte de la zona de uso moderado salvo su extremo occidental que se incluiría en la zona de exclusión.

\section{Zona de uso restringido (Restauración 3)}

Posee valor paisajístico y alberga algunas especies vegetales de gran interés como Arthrocnemum macrostachyum y Limonium papillatum. Incluye también elementos geomorfológicos diversos como callaos, acumulaciones lávicas, malpaís y plataformas arenoarcillosas. Está afectado por la entrada de vehículos y la presencia de pequeños depósitos de escombro. Se recomienda la prohibición del tráfico de vehículos por leve que sea y la eliminación de los desechos urbanos, así como de los restos de construcciones (bloques e hitos de hormigón, partes de estructuras metálicas, etc.). Una vez rehabilitada se incluiría en la zona de uso moderado. 


\section{Zona de uso moderado}

Podemos distinguir tres sectores: el oriental formado por una pequeña playa y un arenal con paleodunas; el occidental constituido por un malpaís en buen estado y recubierto por líquenes y, finalmente, el meridional situado por detrás de la pista. Los dos primeros sectores podrían tener un uso recreativo y pedagógico, en tanto que el sector situado más al sur se halla muy degradado por lo que actualmente carece de interés. Sin embargo, si la evolución fuese progresiva podría ser colonizado por la vegetación y habitado por la fauna propia de estos lugares. En este sentido, el Charco de Bristol es hoy en día, pese a todas las agresiones un reservorio trófico de aves limícolas, acuáticas y esteparias que con las condiciones adecuadas podrían también nidificar. De hecho, el saladar está incluido dentro de la franja "Corralejo - Faro del Tostón" del Programa de Conservación de las Áreas Importantes para las Aves de BirdLife (Important Bird Areas, IBA).

\section{CONCLUSIONES}

El saladar de Bristol, de titularidad pública, ha sufrido una importante degradación en las últimas cuatro décadas y carece de protección. No obstante, este pequeño enclave cuenta con unos valores naturales y paisajísticos de gran interés científico, los cuales pueden preservarse a través de una adecuada gestión ambiental al amparo de políticas locales y regionales basadas en el desarrollo sostenible. Entre otros elementos cabe destacar su patrimonio geomorfológico constituido por áreas de malpaís, arenales, plataformas de abrasión marina, depósitos de cantos rodados y la propia depresión litoral; y, sobre todo, el vegetal que, pese a ocupar una extensión muy reducida, posee una amplia diversidad caracterizada por la presencia de comunidades incluidas en la Directiva de Hábitats (Zygophyllo fontanesii - Arthrocnemetum macrostachyi, Frankenio capitatae - Suaedetum verae, Frankenio capitatae - Zygophyllum fontanesii) y de suma singularidad para Fuerteventura como Sarcocornietum perennis. El delicado estado de conservación del patrimonio vegetal del saladar sólo se puede corregir y mejorar eliminando las agresiones que sufre diariamente, para lo cual hemos formulado una propuesta de restauración basada en la zonificación de cinco unidades, con la finalidad última de que sirva de base para su declaración como Sitio de Interés Científico.

\section{BIBLIOGRAFÍA}

ANCOCHEA, E., BRANDLE, J.L., CUBAS, C.R., HERNÁN, F. y HUERTAS, M.J. (1993): La Serie I de la isla de Fuerteventura. Madrid. Mem. de la Real Acad. de Cienc. Ex. Fís. y Nat.

AROZENA, M.E. (2000): «Estructura de la vegetación» en Metodología y práctica de la Biogeografía (Meaza, G., Coord.). Madrid, Ediciones del Serbal, 77-146.

ASCAN (1981): En defensa del Jable de Corralejo. Las Palmas de Gran Canaria. ASCAN.

BELTRÁN, E., AROZENA, M.E. y RÍOS, J. (1999): «El papel de la morfología superficial de las coladas lávicas en las características de la vegetación del malpaís de Güímar (Tenerife, I. Canarias)» en Professor Joan Vilà Valentí (VV.AA.). Barcelona, Universitat de Barcelona, 783-799. 
CRIADO, C. (1990): «La evolución del paisaje vegetal de Fuerteventura a través de fuentes escritas (s. XV - XIX)». Tebeto (Anuario del Archivo Histórico Insular de Fuerteventura, Islas Canarias), n 3, 249 -259.

CRIADO, C. (1991): La evolución del relieve de Fuerteventura. Puerto del Rosario. Servicio de Publicaciones del Cabildo Insular de Fuerteventura.

CRIADO, C., GUILlOU, H., HANSEN, A., HANSEN, C., LILlO, P., TORRES, J.M. y NARANJO, A. (2004): «Geomorphological evolution of Parque Natural de Las Dunas de Corralejo (Fuerteventura, Canary Islands)» en Contribuciones Recientes sobre Geomorfología (Benito, G. y Díez Herrero, A., Eds.). Madrid, SEG y CSIC, 291-297.

CRIADO, C., GUIlloU, H., HANSEN, A., HANSEN, C., LILlO, P., TORRES, J. M. y NARANJO, A. (2007): «Mapa Geomorfológico del Parque Natural de las Dunas de Corralejo (Fuerteventura). XIII Jornadas de estudio de Lanzarote y Fuerteventura, 2, 399-427.

CRIADO, C., TORRES, J.M., HANSEN, A., LILLO, P. y NARANJO, A. (2012): «Intercalaciones de polvo sahariano en paleodunas bioclásticas de Fuerteventura (Islas Canarias)». Cuaternario y Geomorfología, vol. 26 (1-2), 73-88.

COELLO, J., CANTAGREL, J.M., HERNÁN, F., FÚSTER, J.M., IBARROLA, E., ANCOCHEA, E., CASQUET, C., JAMOND, C., DÍAZ DE TERAN, J. R. y CENDRERO, A. (1992): «Evolution of the Eastern Volcanic Rigde of the Canary Islands Based on New K-Ar Data». Jour. Volc. Geoth. Res., n' 53, 251-274.

CUBAS, C.R., FERNÁNDEZ, S., HERNÁNDEZ-PACHECO, A., HERNÁN, F. y DE LA NUEZ, J. (1988): «Los domos sálicos de Fuerteventura». Revista de Materiales y Procesos Geológicos, $\mathrm{n}^{\circ}$ 6, 71-97.

DEL ARCO, M. J., WILDPRET, W., PÉREZ DE PAZ P.L., RODRÍGUEZ DELGADO, O., ACEBES, J.R., GARCÍA GALLO, A., MARTÍN V.E., REYES BETANCORT, J.A., SALAS, M., BERMEJO, J.A., GONZÁLEZ, R., CABRERA, M.V., GARCÍA, S. (2006): Mapa de Vegetación de Canarias. Santa Cruz de Tenerife. GRAFCAN.

DEL ARCO, M. J., GONZÁLEZ, R., GARZÓN, V., y PIZARRO, B. (2010): «Actual and potential natural vegetation on the Canary Islands and its conservation status». Biodiversity and Conservation, 19, 3089-3140.

DIRECCIÓN GENERAL DE COSTAS (2006): Estudio del estado actual de los sistemas dunares de Corralejo y Jandía (Fuerteventura). Identificación de 252 problemas y propuestas de actuación. Madrid. Ministerio de Medio Ambiente (memoria inédita).

DÓNIZ, F.J. (2009: «Patrimonio geomorfológico de los volcanes basálticos monogénicos de la caldera de Gairía-Malpaís Chico y el Malpaís Grande en la isla de Fuerteventura (Canarias, España)». Nimbus, n 23-24, 89-103.

DORTA, P.J. (1996): «Las inversiones térmicas en Canarias». Investigaciones Geográficas, $\mathrm{n}^{\mathrm{o}} 15,109-126$.

ESPINAR, J.L. (2009): «1420 Matorrales halófilos mediterráneos y termoatlánticos (Sarcocornetea fruticosi)» en Bases ecológicas preliminares para la conservación de los tipos de hábitat de interés comunitario en España (VV.AA.). Madrid, Ministerio de Medio Ambiente, y Medio Rural y Marino.

FERNÁNDEZ, E., ROCA, E., CABRERA, L., HERNÁNDEZ-CALVENTO, L., y PÉREZCHACÓN, E. (2012): «Estudio de la percepción social en el entorno del Parque Natural 
de las Dunas de Corralejo (Fuerteventura, Islas Canarias): aplicaciones para la gestión integrada de zonas costeras». I Congreso Iberoamericano de Gestión Integrada de Áreas Litorales, 1186-1196.

FERNÁNDEZ, M., SANTOS, A. y DOMÍNGUEZ, F. (1982): «El complejo dunar de Corralejo (Fuerteventura)». Gaceta de Canarias, n 3, 73-83.

FERNÁNDEZ, M. y SANTOS, A. (1983): «La vegetación del litoral de Canarias, 1. Arthrocnemetea». Lazaroa, $\mathrm{n}^{\circ}$ 5, 143-155.

FERNÁNDEZ CALDAS, E., DE LA CRUZ, M., JIMÉNEZ, C., y TEJEDOR SALGUERO, M. L. (1989): «Suelos de la isla de Fuerteventura» en Simposio internacional de la explotación caprina en zonas áridas. Puerto del Rosario. Servicio de Publicaciones del Excmo. Cabildo Insular de Fuerteventura. 353-360.

FERNÁNDEZ-CABRERA, E., PÉREZ-CHACÓN ESPINO, E., CRUZ AVERO, N., HERNÁNDEZ-CORDERO, A. y HERNÁNDEZ-CALVENTO, L. (2011): «Consecuencias ambientales del crecimiento urbano-turístico en el sistema de dunas de Corralejo (Fuerteventura-Islas Canarias)». XXII Congreso de Geógrafos Españoles. Urbanismo expansivo: de la utopía a la realidad. 241-252.

FERNÁNDEZ-PELLO. L., PÉREZ-CHACÓN, E. y QUIRANTES, F. (1985): «Organización del paisaje de un espacio microinsular, en medio semiárido (islote de Lobos, Fuerteventura, Canarias)». IX Coloquio de Geografía, Tomo I. Murcia.

FÚSTER, J.M., CENDRERO, A., GASTESI, P., IBARROLA, E. y LÓPEZ-RUIZ, J. (1968): Geología y vulcanología de las Islas Canarias. Fuerteventura. Madrid. Inst. Lucas Mallada, CSIC.

GARCÍA, L., PÉREZ-CHACÓN, E., HERNÁNDEZ, A.I. y HERNÁNDEZ, L. (2014): «Cartografía de la distribución espacial de la cobertura vegetal en sistemas arenosos áridos: análisis comparado de métodos aplicados en La Graciosa (Islas Canarias, España)» en Biogeografía de sistemas litorales. Dinámica y conservación (Cámara, R., Rodríguez, B. y Muriel, J.L., Eds.). Sevilla, Universidad de Sevilla, 21-26.

GOBIERNO DE CANARIAS (2009): Evaluación de especies amenazadas de Canarias. Consejería de Medio Ambiente. Dirección General del Medio Ambiente. Servicio de Biodiversidad.

HERNÁNDEZ, A.I, PÉREZ-CHACÓN, E. y HERNÁNDEZ, L. (2014): «Dinámica de la comunidad de Tamarix Canariensis en el campo de dunas de Maspalomas (Gran Canaria, Islas Canarias)» en Biogeografía de sistemas litorales. Dinámica y conservación (Cámara, R., Rodríguez, B. y Muriel, J.L., Eds.). Sevilla, Universidad de Sevilla, 15-19.

HERNÁNDEZ-CORDERO, A. I., PÉREZ-CHACÓN, E. y HERNÁNDEZ-CALVENTO, L. (2008): «Aplicación de tecnologías de la información geográfica al estudio de la vegetación en sistemas de dunas litorales. Resultados preliminares en el campo de dunas de Maspalomas (Gran Canaria, Islas Canarias)» en Tecnologías de la Información Geográfica para el Desarrollo Territorial (Hernández, L. y Parreño, J. M., Eds.). Las Palmas de Gran Canaria, Servicio de Publicaciones y Difusión Científica de la ULPGC, 603-617.

HERNÁNDEZ-CORDERO, A. I., PÉREZ-CHACÓN, E. y HERNÁNDEZ-CALVENTO, L. (2015): «Vegetation, distance to the coast, and aeolian geomorphic processes and landforms in a transgressive arid coastal dune system». Physical Geography, 36 (1), 60-83. 
IBARROLA, E., FÚSTER, J.M. y CANTAGREL, J. M. (1989): «Edades K-Ar de las rocas volcánicas submarinas en el sector norte del Complejo Basal de Fuerteventura». ESF Meeting on Canarian Volcanism. 124-128.

KUNKEL, G. (1977): «Las plantas vasculares de Fuerteventura (Islas Canarias), con especial interés de las forrajeras». Naturalia Hispanica, $\mathrm{n}^{\circ}$ 8, 1-131. Madrid. Ministerio de Agricultura, Alimentación y Medio Ambiente.

LÓPEZ, J. y LÓPEZ, A. (1979): «El clima de Canarias según la clasificación de Köppen». Estudios Geográficos, vol. 16, n $\mathrm{n}^{\mathrm{0}}$ 58, 5-21.

MARZOL, M.V. (1988): La lluvia, un recurso natural para Canarias. Santa Cruz de Tenerife. Caja General de Ahorros de Canarias.

MARZOL, M.V. (1993): «Los factores atmosféricos y geográficos que definen el clima de archipiélago canario» en Aportaciones en homenaje al profesor Luis Miguel Albentosa. Tarragona, Diputación de Tarragona, 151-176.

MINISTERIO DE MEDIO AMBIENTE (2006): Estudio Ecocartográfico del litoral de las islas de Fuerteventura y Lobos. Madrid. Ediciones Tuomaï.

MORA HERNÁNDEZ, J.L., ARBELO RODRÍGUEZ, C.D. y RODRÍGUEZ RODRÍGUEZ, A. (2009): «Características de los suelos de las Islas Canarias en relación a la vegetación natural», en Homenaje al Prof. Dr. Wolfredo Wildpret de la Torre (Beltrán Tejera, E., Afonso-Carrillo, J., García Gallo, A. y Rodríguez Delgado, O. Eds). La Laguna. Instituto de Estudios Canarios, 665-684.

MORALES DELGADO, E. (2009): «Extracción de datos del Banco de Datos de Biodiversidad de Canarias para la evaluación de especies amenazadas. Ficha de Evaluación: Sarcocornia perennis». Actualización y análisis de los datos de las Especies Amenazadas de Canarias. Colegio Oficial de Biólogos de Canarias-Viceconsejería de Medio Ambiente del Gobierno de Canarias.

PADRÓN MEDEROS, M. A. (2012): Caracterización morfológica y genética de especies arbustivas de los géneros Salsola L. y Suaeda Forssk. ex J.F. Gmel. en las Islas Canarias. Tenerife. Servicio de publicaciones de la Universidad de la Laguna.

PÉREZ-CHACÓN ESPINO, E., HERNÁNDEZ CALVENTO, L. y YANES LUQUE, A. (2007): «Transformaciones humanas y sus consecuencias sobre los litorales de las islas Canarias», en Les littoraux volcaniques: une approche environnementale (Paris, R. y Etienne, S., Eds.). Clermont-Ferrand, Presses universitaires Blaise Pascal, 173-191.

PUGNAIRE, F. I., ARMAS, C. y VALLADARES, F. (2004): «Soil as a Mediator in PlantPlant Interactions in a Semi-Arid Community». Journal of Vegetation Science, $\mathrm{n}^{\circ} 15$, 85-92.

RIVAS-MARTÍNEZ, S., T. E. DÍAZ, F. FERNÁNDEZ-GONZÁLEZ, J. IZCO, J. LOIDI, M. LOUSÃ y A. PENAS (2002): «Vascular plant comunities of Spain and Portugal». Itinera Geobot. $\mathrm{n}^{\circ} 15(1,2), 5-922$.

RODRÍGUEZ DELGADO, O., GARCÍA GALLO, A. y REYES BETANCORT, J. A. (2000): «Estudio fitosociológico de la vegetación actual de Fuerteventura (Islas Canarias)». Vieraea: Folia scientarum biologicarum canariensium, $\mathrm{n}^{\circ} .28,61-98$.

RODRÍGUEZ DELGADO, O (Ed.) (2005): Patrimonio natural de la isla de Fuerteventura. Tenerife. Cabildo de Fuerteventura. Centro de la Cultura Popular Canaria. Consejería de Medio Ambiente y Ordenación Territorial. 
RODRÍGUEZ NÚÑEZ, S. y VALDIVIA MARTÍN, C. (2009): Evaluación de especies catalogadas de Canarias. Sarcocornia perennis. Expte Sarper 11/2009. Gobierno de Canarias. Dirección General del Medio Natural, Servicio de Biodiversidad.

ROMERO, C. (1986): «Aproximación a la sistemática de las estructuras volcánicas complejas de las Islas Canarias». Ería. Revista de Geografía, n 11, 211-223.

SADEK, L. A. y ELDARIER, S. M. (1995): «Cyclic Vegetation Change and Pattern in a Community of Arthrocnemum macrostachyum in Mediterranean Coastal Desert». Journal of arid Environment, $\mathrm{n}^{\mathrm{o}}$ 31, 67-76.

SANTANA, A., DÍAZ, P. y RODRÍGUEZ, P. J. (2011): «Renovación de destinos y percepción de la protección ambiental: El caso de Fuerteventura (Islas Canarias, España)». Investigaciones Turísticas, $\mathrm{n}^{\circ}$ 1, 1-20.

SANTANA LÓPEZ, I. y NARANJO MORALES, M. (2002): «Sarcocornia perennis (Miller) A. J. Scott. Fuerteventura» en Seguimiento de Poblaciones de Especies Amenazadas 2002. Consejería de Medio Ambiente y Ordenación Territorial.

ZAZO, C., HANSEN, A., GOY, J. L., CRIADO, C., GONZÁlEZ-DELGADO, J. A., DABRIO, C. J. y GHALEB, B. (2008): «Geomorfología volcánica y variaciones del nivel del mar en Lanzarote y Fuerteventura (Plio-Cuaternario)». Itinerarios Geológicos por las Islas Canarias. Lanzarote y Fuerteventura, Tenerife, La Gomera y El Hierro, 6, 143-172. 